\title{
Delineation of ecological provinces using ocean colour radiometry
}

\author{
Emmanuel Devred ${ }^{1,2, *}$, Shubha Sathyendranath ${ }^{3}$, Trevor Platt $^{2}$ \\ ${ }^{1}$ Department of Oceanography, Dalhousie University, Halifax, Nova Scotia B3H 4J1, Canada \\ ${ }^{2}$ Ocean Science Division, Bedford Institute of Oceanography, Box 1006, Dartmouth, Nova Scotia B2Y 4A2, Canada \\ ${ }^{3}$ Plymouth Marine Laboratory, Prospect Place, The Hoe, Plymouth PL1 3DH, UK
}

ABSTRACT: In 2003, Canadian Surface Ocean Lower Atmosphere Study conducted 3 research expeditions (April-May, July and October) to the Northwest Atlantic to study gas exchange at the air-sea interface. Interpreting the relationships between gas exchange and biological activity measured in these expeditions is facilitated if the water masses sampled can be identified in a large-scale context. Longhurst et al. (1995) tackled the issue of water mass characterisation by defining biogeochemical provinces for the world ocean and in particular for the NW Atlantic. To avoid the limitations that arise from the static arrangement of provinces with rectilinear boundaries as used in Longhurst et al. (1995), we developed a dynamic method based on statistical analysis of geophysical and biological data to delineate the boundaries of Longhurst's provinces in real time. This new method was applied to satelliteretrieved sea-surface temperature (SST) and phytoplankton biomass data averaged over the length of the research cruises $(22,17$ and $16 \mathrm{~d}$ in spring, summer and fall respectively). CTD casts at various stations along the ship track were used to validate the method. A sensitivity study on primary production estimations performed with both definitions (static and dynamic) showed a negligible difference at the basin scale; however, variations at the province scale were significant. The regional description afforded by the new method was useful for the interpretation of expedition data.

KEY WORDS: Ecological provinces - Remote sensing • Ocean colour · Sea surface temperature - Statistical analysis · Northwest Atlantic Ocean

Resale or republication not permitted without written consent of the publisher

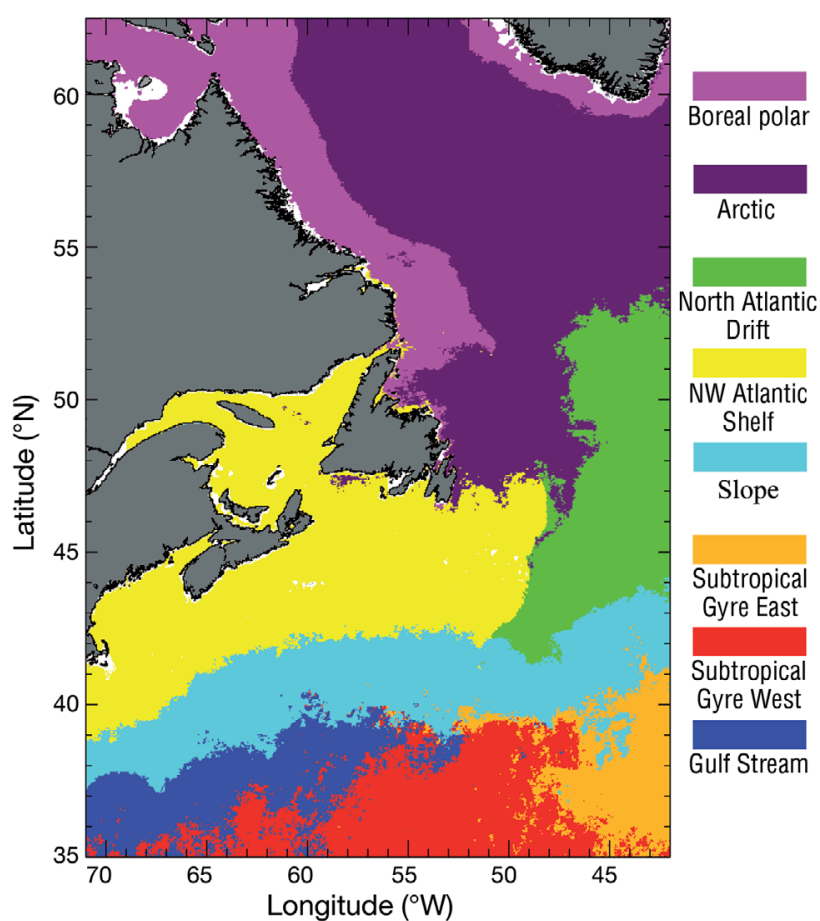

Dynamic assignment of ecological provinces in the NW Atlantic Ocean, using ocean colour radiometry (April 24 to May 15, 2003).

Image: E. Devred (based on NASA satellite data)

\section{INTRODUCTION}

The Surface Ocean Lower Atmosphere Study (SOLAS), an international research program that started in 2000, focuses on air-sea interface gas exchanges and related processes. The Canadian com- 
ponent of SOLAS (C-SOLAS) is dedicated to 3 main research themes: (1) biogeochemical interactions and feedback between the ocean and atmosphere, (2) exchange processes at the ocean-atmosphere interface, and (3) integration and modelling of interactions between the ocean and atmosphere. In 2003, C-SOLAS activities included 3 cruises to the NW Atlantic, 1 in each of 3 seasons. The cruises were designed to study greenhouse gas exchanges across the air-sea interface and related processes in various ecological provinces in the area. The same stations were occupied during each cruise. A challenge for interpreting data collected at these stations and for extrapolating the results over large areas was the identification of the ecological provinces where the stations were located. The problem was more acute when the sampling stations were located near the boundaries of the putative provinces. This issue has been addressed at global (Sathyendranath et al. 1995, Longhurst et al. 1995, Longhurst 2006) and basin scales (Hoepffner et al. 1999, Watts et al. 1999, Gibb et al. 2000, Gonzalez-Silvera et al. 2004).

Ecological provinces, also referred to as biogeochemical provinces, are regions or water masses with similar physical (e.g. SST, mixed-layer depth, bathymetry) and biological (e.g. chl a concentration, photosynthetic parameters, biomass vertical profile) characteristics. Longhurst et al. (1995) proposed a global classification of ecological provinces, based on physical forcing, in which oceans were partitioned into 56 provinces. We used these provinces as a template and assigned to them photosynthetic parameters and parameters that describe vertical structure in chl a distribution for computing primary production. The main limitation of the approach, acknowledged by Longhurst et al. (1995), lies in the static definition of the province boundaries: ocean circulation and therefore water mass location change with seasonal cycles or in response to intense atmospheric events (see also Platt \& Sathyendranath 1999).

Satellite observations are useful in identifying physical ocean processes and features such as fronts and eddies (Cornillon et al. 1987, Sur et al. 1994, Bardey et al. 1999, Johannessen et al. 2000, Hoge \& Lyon, 2005). This information could be applied to aid in assigning dynamic province boundaries, which would be superior to the static boundaries that have been used so far. Several authors have used satellite data to identify surface water masses and to compute phytoplankton production at basin scales (Dugdale et al. 1989, Sathyendranath et al. 1991, Watts et al. 1999, Fischer et al. 2000). These methods are based on SST and chl $a$ concentration. Here, using data from the NW Atlantic Ocean, we build on these studies to develop a dynamic method for ecological partitioning of the ocean in real time. This study focuses on the NW Atlantic region so that only a fraction of the initial provinces described by Longhurst et al. (1995) account for the various ecosystems present in the study area: Boreal Polar (BPLR), Arctic (ARCT), North Atlantic Drift (NADR), Northwest Continental Shelf (NWCS), Gulf Stream (GFST), Subtropical Gyre East (STGE) and Subtropical Gyre West (STGW). A detailed description of the physical and biological characteristics of the provinces can be found in Longhurst (2006).

The new method is based on cluster analysis performed on remotely sensed data (SST and chl a) from the Moderate Resolution Imaging Spectroradiometer (MODIS). The method was applied to 3 periods corresponding to the $3 \mathrm{C}$-SOLAS research cruises. Vertical profiles of chl $a$ and temperature were examined to see how well they conform to the independently assigned provinces. Primary production was then computed using both the static and dynamic approaches for defining province boundaries. Whereas total production for the entire study area was similar in magnitude for both approaches, primary production at the province scale showed some differences.

\section{MATERIALS AND METHODS}

Satellite observation. The 3 C-SOLAS cruises were conducted in 2003 in spring (25 April to 15 May), summer (8 to 24 July) and fall (13 to 28 October). Daily MODIS L2 data from the AQUA platform were downloaded from the NASA website (http://oceancolor.gsfc. nasa.gov/) for each cruise. SST and chl a concentration were extracted for the study area, which extends from 35 to $62^{\circ} \mathrm{N}$ and from 42 to $71^{\circ} \mathrm{W}$ (Fig. 1). Some 173, 124 and 111 images were used, respectively, for the spring, summer and fall cruises. The large number of files (compared with the number required to accomplish the same task with SeaWiFS, for example) is characteristic of MODIS data; files are archived and distributed as images, each corresponding to $5 \mathrm{~min}$ of satellite data acquisition.

For each cruise, the data were remapped using the SeaDAS software (NASA). A cylindric projection was used with a spatial resolution of $2.25 \mathrm{~km}^{2}(1.5 \times 1.5 \mathrm{~km})$, giving a matrix of 1360 pixels $\times 1956$ lines for the study area. The individual remapped images were combined to provide composite images of SST and chl a concentrations for the periods of the 3 C-SOLAS cruises. Fig. 2 shows SST and chl a concentration for the spring cruise. The large-scale structures can be intuitively interpreted as an assemblage of different water masses outcropping at the surface. For example, in the south of the study area, warm oligotrophic waters (WOW) form a front against cool, phytoplankton-rich waters. Such features were exploited to identify and separate the different ecological provinces. In addition to chl a concentra- 


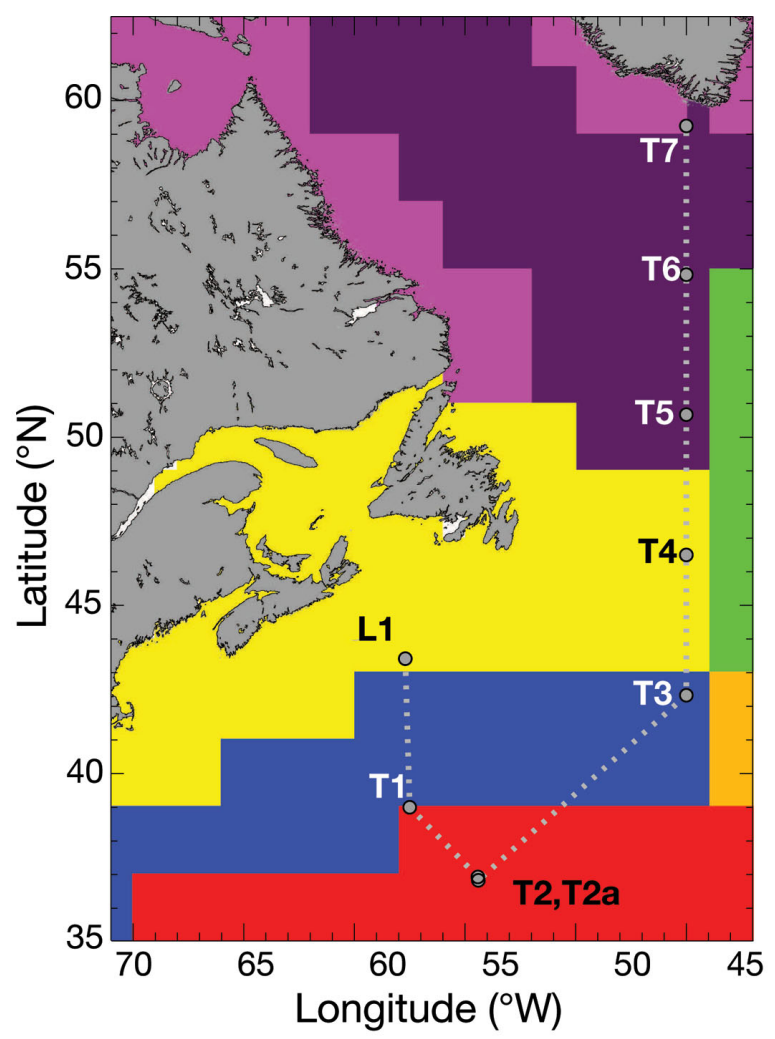

BPLR ARCT NADR NWCS GFST STGE STGW

Fig. 1. Static boundaries of ecological provinces in the NW Atlantic defined by Longhurst et al. (1995) and location of the stations with SST and chl a concentration profiles. See Table 2 for definitions of province names

tion and SST, 4 other variables were used in the statistical analysis: bathymetry, location (latitude and longitude) and a province number ranging from 0.25 to 1.75 allocated to each pixel depending on that pixel's original location assignment among the static ecological provinces of Longhurst et al. (1995). The value of the province number depended on the location of the province: the smallest number is the farthest north: Boreal Polar $(B P L R)=0.25$, Arctic $(A R C T)=0.5$, North Atlantic Drift $($ NADR) $=0.75$, NW Atlantic Shelf $($ NWCS $)$ = 1, Gulf Stream (GFST) 1.25, Subtropical Gyre East $(\mathrm{STGE})=1.5$, and Subtropical Gyre West $($ STGW $)=1.75$.

In situ measurements. CTD casts were made at 8 stations during each of the 3 cruises. Station numbers and locations are summarised in Table 1. Station locations were selected to cover a wide range of water masses, from the Sargasso Sea in the south of the study area to the Greenland shore in the north (Fig. 1). The most northerly, Stn T7, was not sampled during the spring cruise due to a lack of ship time. Stn T2a, near Stn T2, was sampled only during the spring cruise. At each station, 2 to 8 profiles were made depending on time
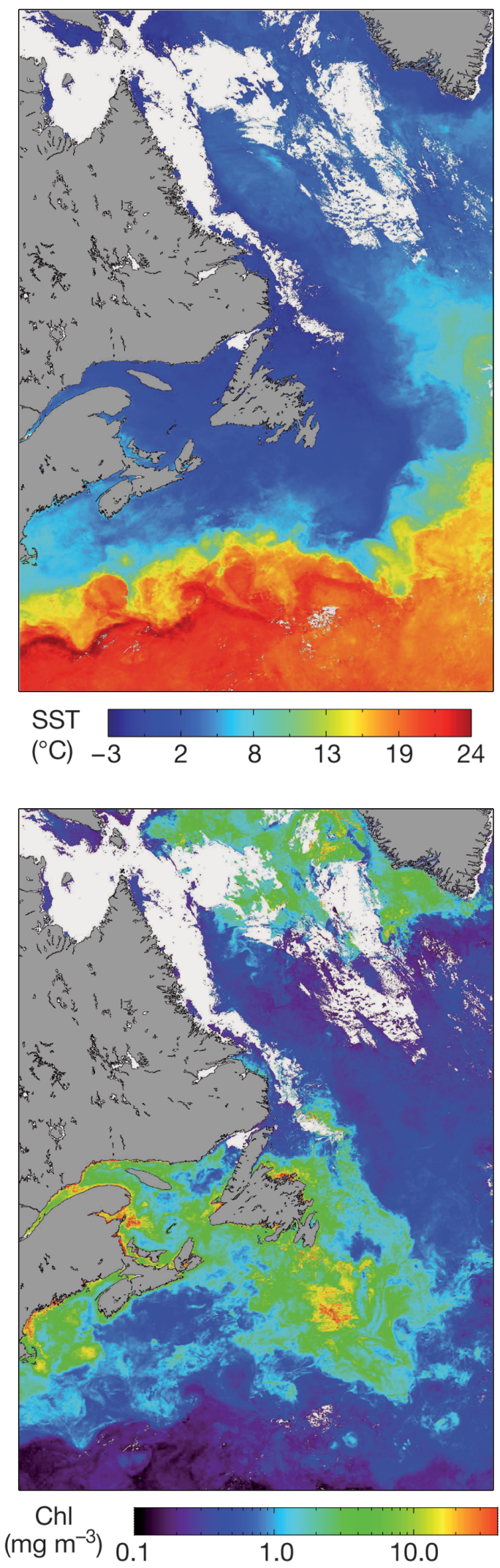

Fig. 2. Composite images of SST and chl a computed using MODIS data from 25 April to 15 May 2003 in the NW Atlantic 
Table 1. Station locations. Stn T2a was visited only during the spring cruise

\begin{tabular}{|lcc|}
\hline Stn ID & $\begin{array}{c}\text { Latitude } \\
\left({ }^{\circ} \mathrm{N}\right)\end{array}$ & $\begin{array}{c}\text { Longitude } \\
\left({ }^{\circ} \mathrm{W}\right)\end{array}$ \\
\hline L1 & 43.41 & 57.70 \\
T1 & 39.00 & 57.50 \\
T2 & 36.83 & 54.40 \\
T2a & 36.93 & 54.42 \\
T3 & 42.33 & 45.00 \\
T4 & 46.50 & 45.00 \\
T5 & 50.67 & 45.00 \\
T6 & 54.83 & 45.00 \\
T7 & 59.58 & 45.00 \\
\hline
\end{tabular}

spent there. Profiles were recorded over depths of several hundred meters. However, only the upper $300 \mathrm{~m}$ were considered in this study, because this depth range included all the information required for primary production calculations (thermocline and depth of chl a maximum). Profiles of temperature and chl a concentration (fluorometry) were used to assess differences between water masses and particular features within a water mass. Measured profiles were assigned to ecological provinces as identified by satellite data, to evaluate the consistency of the statistical analysis. Whereas comparisons with CTD casts do not provide a rigorous validation of the statistical classification of ecological provinces and their dynamical borders, they do lend weight to the classification by demonstrating internal consistency.

Primary production was computed using software developed by Platt \& Sathyendranath (1993), which is freely available on the International Ocean Colour Coordinating Group website (www.ioccg.org/software/ Ocean_Production/; routine: Daily Water Column Production by Numerical Approximation, DWCPN). This program computes the daily water column primary production assuming a Gaussian vertical profile described as:

$$
C(z)=C_{0}+H \exp \left[-\left(z-z_{m}\right)^{2} / 2 \sigma^{2}\right]
$$

where $C$ is chl a concentration at depth $z_{1} C_{0}$ is the background chl a concentration, $z_{m}$ is the depth of chl a maximum, $H$ and $\sigma$ are, respectively, the height and halfwidth of the Gaussian curve that describes the chl a peak, and $\rho^{\prime}=H /\left(H+C_{0}\right)$. These calculations were executed to evaluate the impact of province assignment on production estimates. Parameters of photosynthesis-irradiance curve and of the vertical structure in chl a (Table 2) were taken from Sathyendranath et al. (1995). Some of these parameters are domaindependent, where a domain is made up of a number of provinces: e.g. the polar domain encompasses the BPLR and ARCT provinces. When seasonal variation data was available, it was accounted for in the parameters. Pixels classified as cloudy or ice-covered were not accounted for in the computation, but this does not affect comparisons between the static and dynamic provinces, since the same pixels are missing for both treatments. However, the presence of masked pixels can affect inter-season comparisons at the province scale. Therefore, only cloud-free provinces or provinces with a negligible number of masked pixels over the 3 seasons were used in the analysis.

Statistical analysis. Pixels were assigned to given provinces using an objective, statistical classification procedure: the K-means cluster analysis (Hartigan \& Wong 1979) as implemented in the R freeware (Programming Environment for Data Analysis and Graphics). In this method the user defines the number of clusters into which the data are to be sorted, which is convenient for partitioning an area into a given number of ecological provinces. The K-means method arranges the points of a dataset in $K$ clusters to minimize the system's total variance. The energy $E$ of each cluster for each property $P$ (e.g. SST) is:

$$
E_{K}=\Sigma_{\mathrm{i}=1}^{\mathrm{i}=\mathrm{n}}\left(x_{P, i}-k_{P}\right)^{2}
$$

where $n$ is the number of points in cluster $K_{,} x_{P, i}$ are the values of the data for property $P$, and $k_{P}$ is the value at the centre of cluster $K$ for property $P$. We used 7 clusters and computed 6 centres (SST, chl $a$, water depth, province coefficient, latitude and longitude) for each of the clusters. Thus, 6 -column matrices were created initially for each season with the number of rows equal to the number of valid pixels in the images (excluding clouds and land pixels). The first 2 columns in the matrices corresponded to SST and the logarithm (base 10) of chl a concentration. Before log transformation,

Table 2. Photosynthetic parameters and chl a profiles parameters for the ecological provinces: $\alpha^{B}$ : slope of the relationship between photosynthesis and irradiance; $P_{m}^{B}$ : assimilation number; $z_{m}, \sigma$ and $\rho^{\prime}$ : parameters of the chlorophyll profile as

\begin{tabular}{|c|c|c|c|c|c|c|}
\hline \multicolumn{2}{|c|}{ Province } & 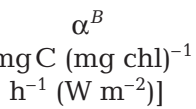 & \multirow{2}{*}{$\begin{array}{c}\begin{array}{c}P_{m}^{B} \\
{\left[\mathrm{mgC}\left(\mathrm{mg} \mathrm{chl}^{-1}\right.\right.} \\
\left.\mathrm{h}^{-1}\right]\end{array} \\
2.5\end{array}$} & \multirow{2}{*}{$\begin{array}{l}Z_{m} \\
(\mathrm{~m}) \\
23\end{array}$} & \multirow{2}{*}{$\begin{array}{c}\sigma \\
(\mathrm{m}) \\
18\end{array}$} & \multirow{2}{*}{$\begin{array}{c}\rho^{\prime} \\
\\
0.87\end{array}$} \\
\hline ARCT & Arctic & 0.10 & & & & \\
\hline BPLR & Boreal Polar & 0.10 & 2.5 & 15 & 18 & 0.83 \\
\hline NADR & North Atlantic Drift & 0.11 & 5.0 & 16 & 19 & 0.87 \\
\hline NWCS & NW Atlantic Shelf & 0.11 & 2.8 & 25 & 19 & 0.82 \\
\hline STGE & Subtropical Gyre East & 0.11 & 5.0 & 56 & 33 & 0.81 \\
\hline STGW & Subtropical Gyre West & 0.11 & 5.0 & 84 & 51 & 0.85 \\
\hline GFST & Gulf Stream & 0.04 & 5.0 & 47 & 35 & 0.91 \\
\hline
\end{tabular}
defined in the text 


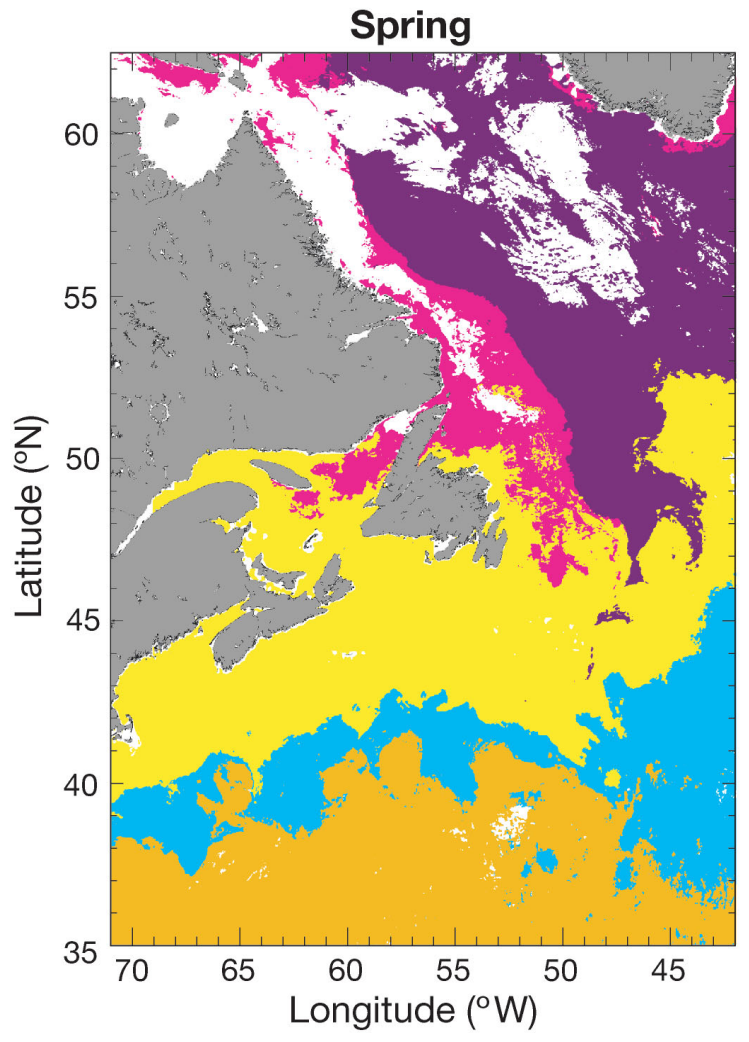

chl a concentrations $>10 \mathrm{mg} \mathrm{m}^{-3}$ were set to $10 \mathrm{mg} \mathrm{m}^{-3}$. The proportion of the total marine pixels set to this threshold value was highest in spring $(2.6 \%)$. With estimated chl $a$ values as high as $200 \mathrm{mg} \mathrm{m}^{-3}$ in some areas (mainly close to the shore), this scaling avoided the organisation of high chl a concentrations into a single cluster during the statistical analysis. The third column of the matrix corresponded to the logarithm of the depth. The log transformation was adopted to restrict the magnitude and range of variation in depth, thus diminishing this variable's weight and avoiding the possibility of bathymetry exercising excessive control over the clustering outcome. The fourth column listed the province number. The coefficients were incremented in steps of 0.25 rather than 1.0 to reduce this column's weight and avoid rectilinear boundaries as observed in the static approach in Longhurst et al. (1995) (Fig. 1). The fifth and sixth columns of the matrix corresponded to the logarithms of each pixel's latitude and longitude, which were used to decrease the magnitude and range of variation of that variable.
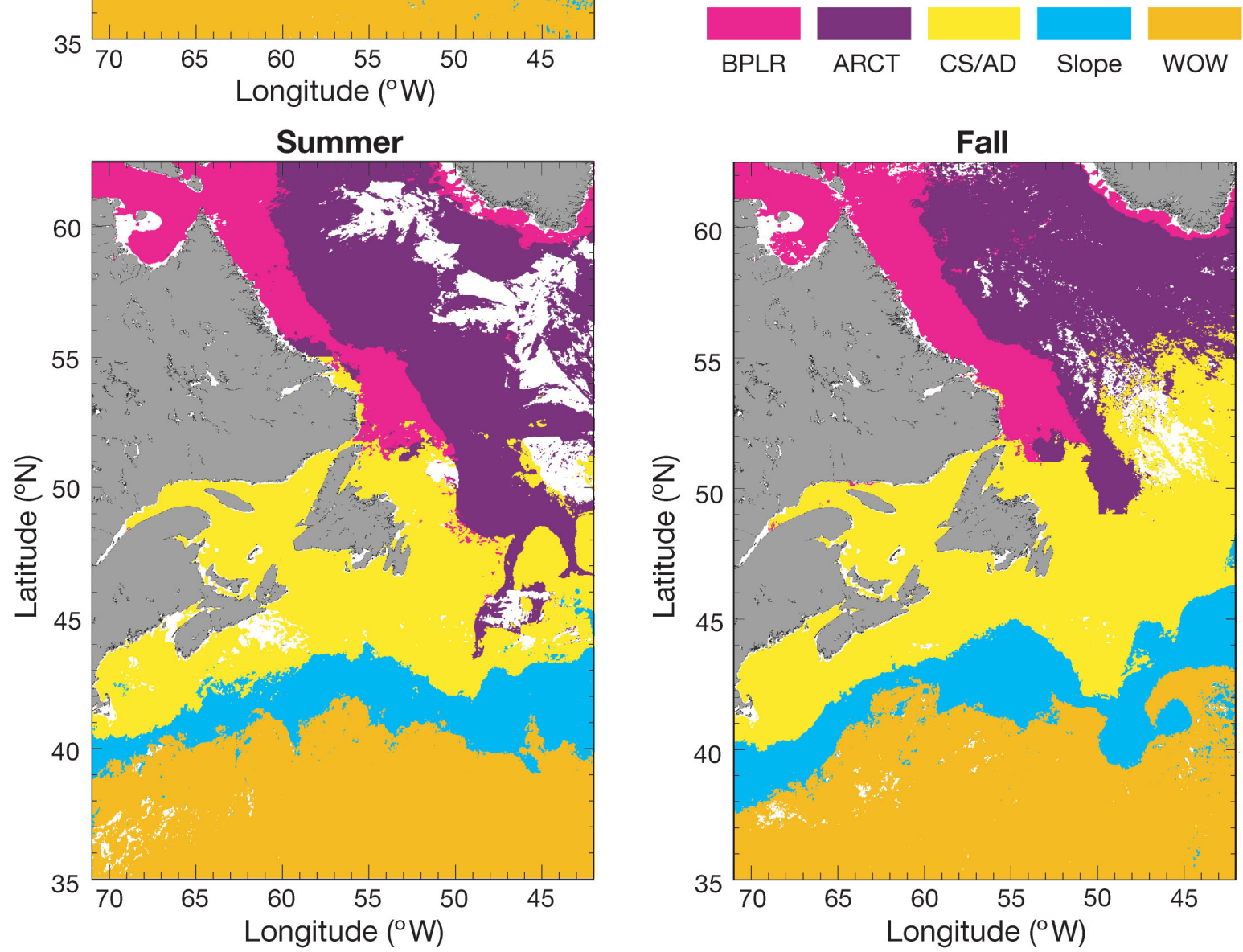

Fig. 3. Identification of water masses using a cluster analysis based on SST (satellite-derived), chl a concentration (satellitederived), bathymetry and location for the 3 C-SOLAS cruises in 2003: April-May (spring), July (summer) and October (fall). BPLR: Boreal Polar province; ARCT: Arctic province; CS/AD: Continental Shelf province/Atlantic Drift; Slope: Slope waters; WOW: warm oligotrophic waters 
To ensure consistency across seasons and to carry identical weight for each data type from one season to another, all data columns except the province identity were linearly scaled as follows: SST from 0 to 10 ; chl $a$ concentration from 0 to 4 ; depth from 0 to 2 ; latitude and longitude from 0 to 1 . Thus SST, chl a concentration and, to a lesser extent, depth were the principal properties in the statistical analysis that drove the allocation of a pixel to a particular province. Several sets of weights were applied to previous statistical analyses (results not shown here). It appears that the set of weights presented above best reproduces the provinces defined by Longhurst et al. (1995) under the implementation of dynamic boundaries.

Identification of provinces. First, datasets for each cruise were processed using the K-means statistical analysis for 7 clusters, the same amount of static provinces in the NW Atlantic as defined by Longhurst et al. (1995). Table 3 presents the coordinates of the centres of each cluster: SST, chl a, depth, province coefficient, latitude and longitude. Note that depth, latitude and longitude are shown (rather than their logarithms) to facilitate interpretation of this tabulation. The statistical analysis returns 5 main surface water masses (Fig. 3) with similar locations in each of the 3 seasons. Because the SST was allocated a broader range of variation (1 to 10, dimensionless), the clusters arranged themselves according to the temperature gradient. Including other properties (depth, province number, latitude and longitude) ensured that pixels with similar chl $a$ and SST values in very differ-

Table 3. Values of the cluster centers after statistical analysis (K-means method) of SST, chl $a$, depth, province ID and location data in the NW Atlantic for the spring, summer and fall C-SOLAS cruises

\begin{tabular}{|lrccccc|}
\hline Cluster & $\begin{array}{r}\mathrm{SST} \\
\left({ }^{\circ} \mathrm{C}\right)\end{array}$ & $\begin{array}{c}\mathrm{Chla} \\
\left(\mathrm{mg} \mathrm{m}^{-3}\right)\end{array}$ & $\begin{array}{c}\text { Depth } \\
(\mathrm{m})\end{array}$ & $\begin{array}{c}\text { Province } \\
\mathrm{ID}\end{array}$ & $\begin{array}{c}\text { Lat. } \\
\left({ }^{\circ} \mathrm{N}\right)\end{array}$ & $\begin{array}{c}\text { Long. } \\
\left({ }^{\circ} \mathrm{W}\right)\end{array}$ \\
\hline Spring & & & & & & \\
1 & -0.31 & 0.81 & 332 & 0.54 & 54.1 & 55.6 \\
2 & 3.52 & 1.10 & 2835 & 0.50 & 56.2 & 49.8 \\
3 & 4.77 & 3.16 & 1468 & 0.98 & 45.5 & 55.5 \\
4 & 16.44 & 0.84 & 4578 & 1.29 & 40.5 & 52.2 \\
5 & 20.08 & 0.29 & 5006 & 1.60 & 37.4 & 56.9 \\
Summer & & & & & & \\
1 & 4.55 & 0.99 & 388 & 0.30 & 58.5 & 59.5 \\
2 & 8.27 & 0.92 & 2918 & 0.51 & 56.0 & 50.8 \\
3 & 12.55 & 1.18 & 863 & 0.96 & 46.3 & 55.7 \\
4 & 21.76 & 0.24 & 4058 & 1.20 & 41.6 & 53.7 \\
5 & 25.70 & 0.12 & 4935 & 1.50 & 37.8 & 56.2 \\
Fall & & & & & & \\
1 & 2.24 & 0.77 & 459 & 0.30 & 58.4 & 60.0 \\
2 & 6.68 & 0.43 & 2894 & 0.47 & 57.9 & 51.1 \\
3 & 11.02 & 1.06 & 1182 & 0.90 & 47.6 & 53.8 \\
4 & 18.48 & 0.39 & 3781 & 1.10 & 42.1 & 54.3 \\
5 & 23.70 & 0.19 & 4950 & 1.50 & 38.2 & 55.1 \\
\hline
\end{tabular}

ent locations would not be sorted into the same cluster.

Fig. 4 shows the cluster centres as functions of SST, chl $a$ and depth for each of the seasons. In all 3 seasons, a cluster characterised by low chl a concentration $\left(0.29,0.12\right.$ and $0.19 \mathrm{mg}$ chl $a \mathrm{~m}^{-3}$ respectively for spring, summer and fall) and high SST (20.1, 25.7 $23.7^{\circ} \mathrm{C}$ respectively for spring, summer and fall) representing WOW was found in the southern part of the study area (Table 3, Cluster 5). Fig. 3 suggests that this cluster subsumes 3 of Longhurst's provinces: GFST, STGE and STGW. A second pool of warm waters (Table 3, Cluster 4) with higher chl a concentration was also found in all 3 seasons (Fig. 4). These waters represent a transition province between the warm and cooler waters in the northern part of the study area.

At the other extreme, cold, phytoplankton-rich waters (Table 3, Cluster 1) with centre values of -0.31 , 4.55 and $2.24^{\circ} \mathrm{C}$ and $0.81,0.99$ and $0.77 \mathrm{mg} \mathrm{chl} a \mathrm{~m}^{-3}$ for spring, summer and fall respectively can be related to Longhurst's BPLR province. Similarly, a second cluster of cold waters $\left(3.52,8.27\right.$ and $6.68^{\circ} \mathrm{C}$ for spring, summer and fall seasons respectively; Table 3 , Cluster 2) is geographically close to the ARCT province defined by Longhurst et al. (1995) (Fig. 3).

Thus, a purely statistical approach does not yield a satisfactory solution from an oceanographic perspective: it does not separate the GFST, STGE and STGW provinces, but keeps them combined in a single cluster (WOW). Moreover, in all 3 seasons, a cluster of warm water with higher chl a concentration was found at deep-water locations (centres of 4578, 4058 and

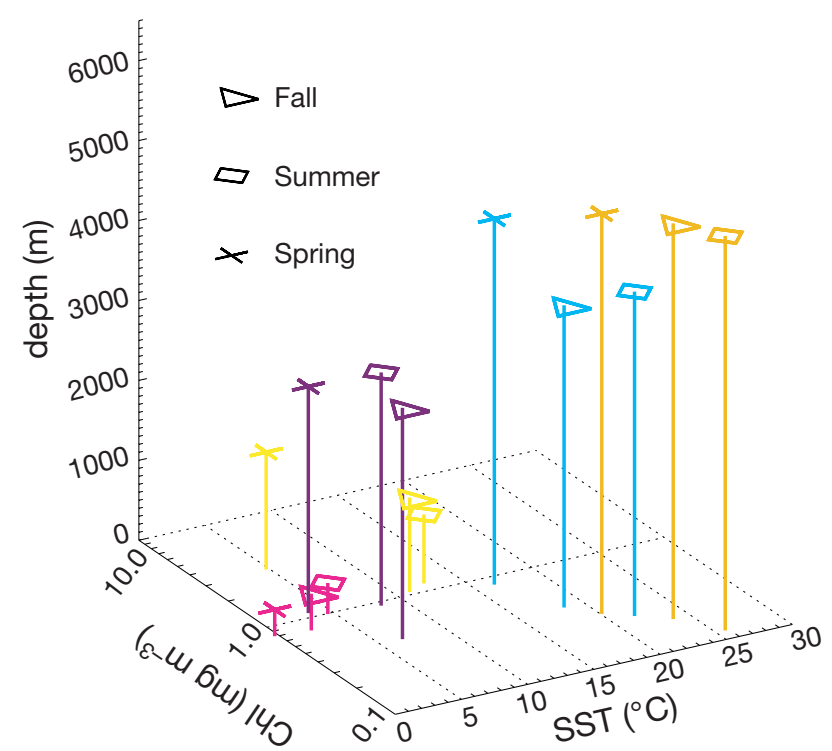

Fig. 4. Centre positions of the 5 subsets resulting from cluster analysis for spring, summer and fall. Only SST, chl a concentration and depth are shown. Colors correspond to provinces shown in Fig. 3 
$3781 \mathrm{~m}$ for spring, summer and fall respectively). Based on this cluster's unique characteristics, it seemed necessary to identify it as a new province to be added to those already defined by Longhurst et al. (1995), and we tentatively call it the Slope Waters. It represents a transition province between the southern WOW and the cooler, richer waters of the continental shelf.

In an analogy between the cluster analysis and Longhurst's province definition, we concluded that Cluster 1 relates to the BPLR province, Cluster 2 to $\mathrm{ARCT}$, Cluster 4 to the new province named Slope, and Cluster 5 encompasses the 3 provinces GFST, STGW and STGE. Thus, Cluster 3 must regroup the NWCS and NADR provinces. This cluster will be referred to as the Continental Shelf / Atlantic Drift (CS/AD) province.

Towards Longhurst et al. (1995) provinces. A second cluster analysis was applied regionally to 2 of the 5 clusters that emerged from the initial partition described above: the WOW and the CS/AD waters. To partition the oligotrophic cluster that emerged from the initial analysis into the GFST, STGE and STGW provinces, we applied K-means cluster analysis to just the WOW, with the number of clusters fixed at 3 . Centre coordinates of the 3 clusters for the 3 seasons are presented in Table 4 . For each season, the cluster with the highest mean SST (Table 4, Cluster 3) was classified as GFST, the most eastern waters (Table 4, Cluster 1) were classified as STGE and the remaining cluster as STGW. The SST and chl a concentrations were the only variables responsible for determining the variations in province boundaries; depth and geographical location for each cluster had the same values in all 3 seasons. However, as the clusters were regrouped across the 3 seasons, some small changes in the mean cluster values for the other variables were noticeable as well. For example, STGW had a mean depth of 5038, 5049 and 5067 m, respectively, in spring, summer and fall.

Table 4. Centre values of the cluster analysis in the oligotrophic warm waters for the spring, summer and fall C-SOLAS cruises in the NW Atlantic

\begin{tabular}{|lccccc|}
\hline Cluster & $\begin{array}{c}\mathrm{SST} \\
\left({ }^{\circ} \mathrm{C}\right)\end{array}$ & $\begin{array}{c}\mathrm{Chl} a \\
\left(\mathrm{mg} \mathrm{m}^{-3}\right)\end{array}$ & $\begin{array}{c}\text { Depth } \\
(\mathrm{m})\end{array}$ & $\begin{array}{c}\text { Lat. } \\
\left({ }^{\circ} \mathrm{N}\right)\end{array}$ & $\begin{array}{c}\text { Long. } \\
\left({ }^{\circ} \mathrm{W}\right)\end{array}$ \\
\hline Spring & & & & & \\
1 & 18.92 & 0.36 & 5037 & 37.5 & 51.7 \\
2 & 20.47 & 0.25 & 5038 & 37.2 & 59.6 \\
3 & 22.19 & 0.21 & 4843 & 37.6 & 64.0 \\
Summer & & & & & \\
1 & 24.67 & 0.15 & 4789 & 39.2 & 53.9 \\
2 & 25.70 & 0.11 & 5049 & 37.4 & 54.1 \\
3 & 26.92 & 0.11 & 4911 & 36.8 & 62.6 \\
Fall & & & & & \\
1 & 22.08 & 0.21 & 4768 & 39.7 & 50.6 \\
2 & 23.65 & 0.18 & 5067 & 37.9 & 52.8 \\
3 & 25.10 & 0.20 & 4966 & 37.1 & 61.6 \\
\hline
\end{tabular}

The CS/AD cluster was also re-analyzed into 2 clusters for each season. The cluster with the highest average longitude (most western) was assigned to the NWCS province.

\section{RESULTS}

\section{Implementation of dynamic provinces}

Generally, the dynamic definition of the ecological provinces (Fig. 5) agreed well with the static definition of Longhurst et al. (1995) (Fig. 1) for all 3 seasons. An objective statistical method (cluster analysis) identified water masses similar to Longhurst et al.'s. The most obvious and immediate result of the new method was that the provinces' rectilinear outlines, a feature of the original static partition that was acknowledged to be unrealistic, disappeared. The new method delineated the boundaries with much higher spatial resolution. The ARCT and BPLR provinces were very close to Longhurst et al.'s initial definition, with the main difference appearing in the BPLR province in spring when it extended further south than initially defined. This is consistent with the ocean circulation in this area: the Labrador Current moves southwards towards the Scotian Shelf in spring (Dupont et al. 2006). The NADR province corresponded to a water mass resulting from the interaction of BPLR waters with NWCS and Slope Waters. Applying cluster analysis to satellite data led to a definition of the NADR province similar to Longhurst's static definition in the north/south direction. However, this water mass extended further to the east than indicated in Longhurst et al. (1995).

The main departures from the original, static definition occurred in the southern part of the study area, mainly due to the addition of a new province, the slope waters: a surface water mass located on the continental slope between the phytoplankton-rich waters of the continental shelf and the phytoplankton-poor (oligotrophic) waters of the Gulf Stream and the subtropical gyre. The new province was located mainly in the area occupied by the GFST province according to Longhurst et al.'s partition. It extended westward, to the south of NADR. The dynamic NWCS province identified during the 3 cruises was smaller than the NWCS province as defined by Longhurst et al. (1995). The dynamic GFST province identified using satellite data was located more to the south than the original, static province. The GFST replaced the western part of the STGW province in Longhurst et al. (1995) such that the dynamic STGW appeared considerably smaller than in the initial static definition, whereas the dynamic STGE province occupied a greater area than in the static definition.

Our analysis showed strong similarities between the static and dynamic definitions of ecological provinces 


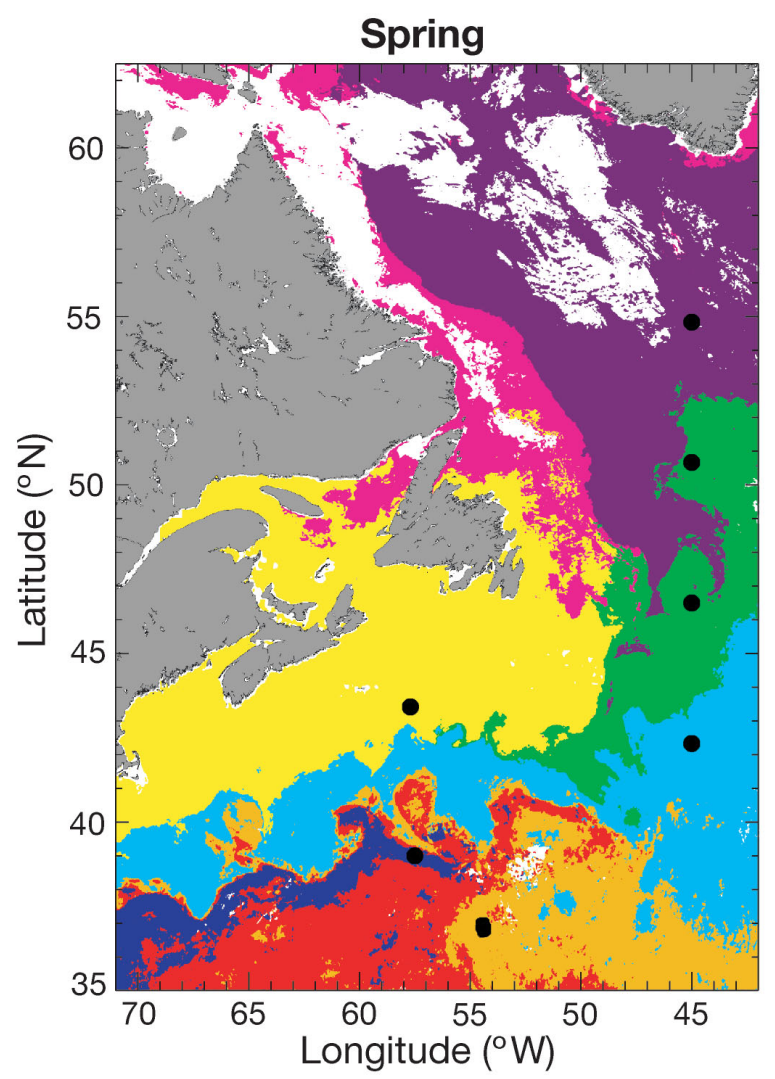

in the NW Atlantic. However, the statistical method based on satellite data (SST and chl a biomass), bathymetry and location provided a more exact and objective definition of the provinces and allowed for seasonal variations. Discontinuities appeared at the borders of the provinces, but in reality, gradients may exist between provinces. This effect is accounted for in the cluster analysis. However, it can result in misclassification of pixels, as observed in Fig. 5, where pixels classified as belonging to the STGW and STGE provinces appeared between the GFST and Slope provinces.

\section{Seasonal variation of the ecological provinces}

One of the benefits of defining the ecological provinces objectively with satellite data is the potential to dynamically identify changes in province boundaries.
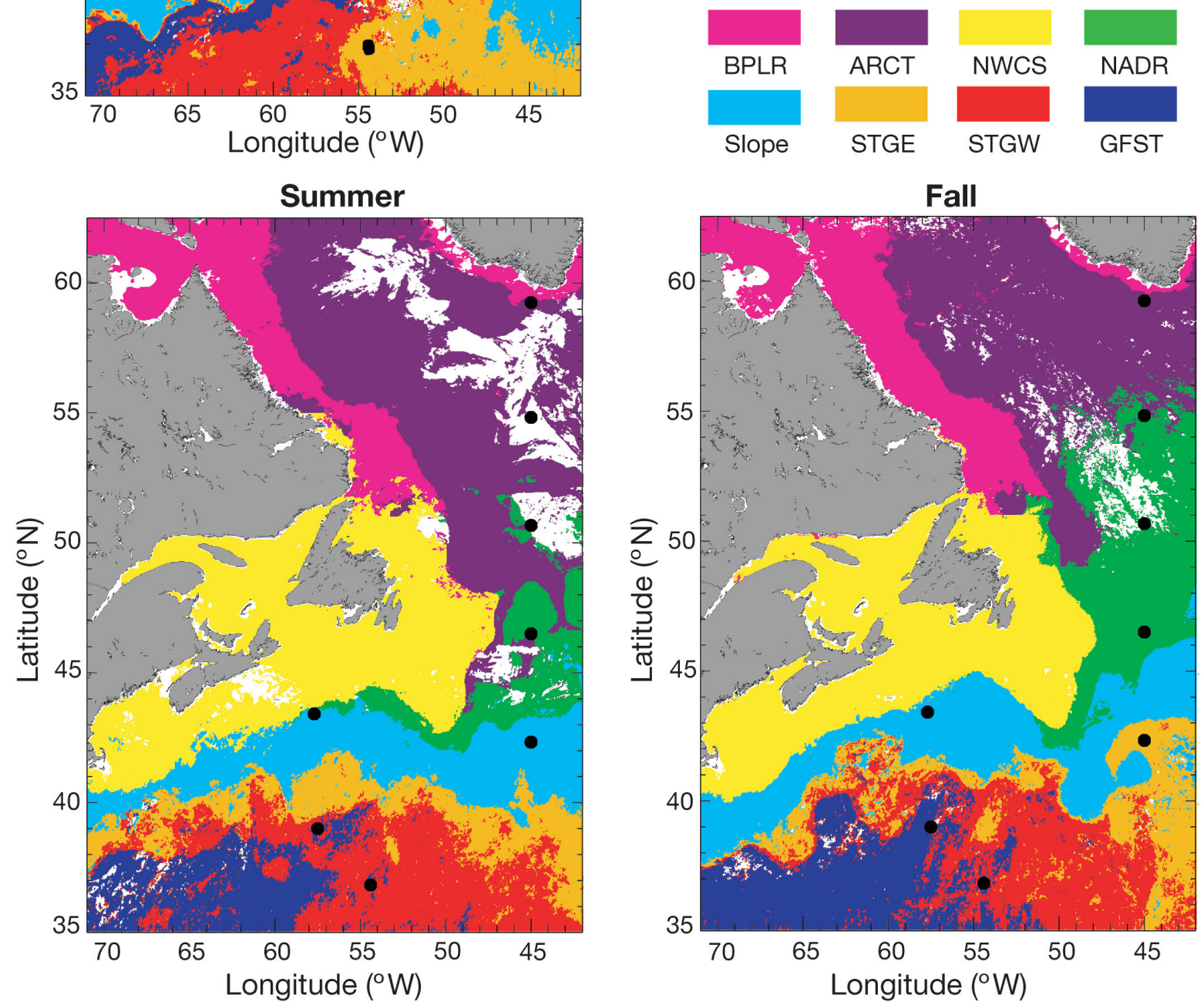

Fig. 5. Dynamical definition of ecological province borders based on the static classification by Longhurst et al. (1995) for the 3 cruises of C-SOLAS in the NW Atlantic in 2003. See Table 2 and Fig. 3 for definitions; $;$ : sampling stations 


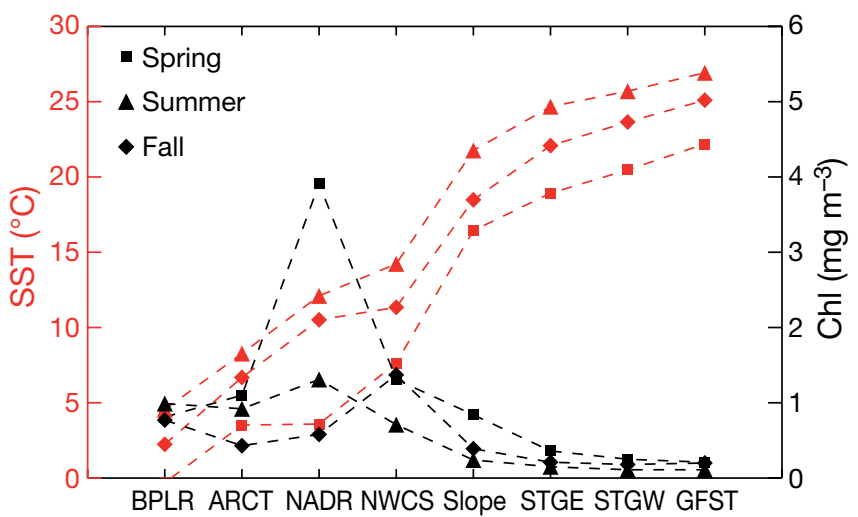

Fig. 6. Mean SST (red) and chl a concentrations (black) for the 8 ecological provinces identified using a cluster analysis on satellite data. See Table 2 and Fig. 3 for definitions

Our goal was to delineate the province boundaries in real time as the data were captured. Although the provinces remained confined to roughly the same region from season to season, fluctuations were significant enough to render the dynamical approach preferable to the static one. As shown in Fig. 5, ecological provinces changed over an annual cycle due to the seasonal warming of the waters. Fig. 6 indicates the variation of the average SST and chl a concentration for each of the 8 provinces for the spring, summer and fall C-SOLAS cruises in 2003. Detailed analysis of the seasonal variations within the ecological provinces would require a higher number of composite images for a given year, e.g. a set of 26 biweekly composite images. Nonetheless, analysing 3 discrete periods over a single year did give an initial view of the different seasonal patterns occurring in this area. It provided the basis for a new conceptual approach that rests on accumulated prior knowledge of the area.

In all provinces, SST was highest in summer when day length is at maximum and the atmosphere is at its warmest (Fig. 6), but the provinces were identifiable throughout the study period. The BPLR province increased in size during the spring as the ice melted. Melt water promoted stratification in the water column, favoring the phytoplankton bloom. These characteristic cold, productive waters made it easy to identify this province.

As the seasons progressed, the waters became warmer and the size of the BPLR province decreased to the advantage of the NWCS province. This province showed the highest chl a concentration in all seasons, with a peak during the spring (average of $3.9 \mathrm{mg}$ chl a $\mathrm{m}^{-3}$ ), which is well documented by Hoepffner \& Sathyendranath (1992). During the summer, pixels near the Labrador Shelf were identified as belonging to the ARCT; pixels located between the BPLR and the NWCS may have been there due to a temperature and/or chl a concentration gradient between those 2 provinces. The NADR province did not vary significantly between seasons, except during the fall when it expanded to the north at the expense of the ARCT province. The NADR province showed the greatest seasonal variation in $\mathrm{SST}\left(>5^{\circ} \mathrm{C}\right.$ between spring and summer) (Fig. 6), in agreement with the oceanographic characteristics described by Longhurst (2006).

The size of the NWCS province remained fairly constant for the 3 seasons. The average chl a concentration in this province remained constant in summer and fall (at least for the period of observation). The northern boundary of the Slope Waters moved slightly northwards as did that of the NWCS province; this water mass represented a buffer between the WOW and the CS/AD. The northern boundary followed the bathymetry of the Scotian Shelf, but the presence of eddies along its border with the NWCS province (particularly in spring) suggests a strong mixing in this area and justifies the use of an objective statistical approach coupled with satellite data.

The WOW were identified using a cluster analysis and can be divided into 3 provinces, the warmest being the GFST. This province broadened from spring to fall, and during the spring strong mixing was visible between the GFST and adjacent provinces (Slope and STGW). The entire system (GFST, STGW and STGE) shifted eastwards as the seasons progressed due to the change in the Gulf Stream path, which impacted the STGW province first, then the STGE province. In summer and fall, small temperature gradients made it difficult to identify the warm oligotrophic provinces. For example, the location of the STGE province north of the GFST province was inconsistent with the definition of Longhurst et al. (1995), but resulted from the temperature gradient between the GFST and the Slope province.

\section{Comparison with CTD profiles}

The large sizes of the provinces militate against a rigorous validation of the dynamic partitioning by comparison with in situ measurements. Only satellite observations allowed data collection over the whole area with adequately repeated coverage. CTD profiles (temperature and fluorometry) were measured at fixed stations in different regions of the study area and gave a good indication of the water masses within which the data were collected. We related the CTD profiles to the ecological provinces defined using the statistical analysis described previously.

In the spring, the temperature profiles did not show stratification and the water column was very well mixed except at Stn T1 (GFST province), where a 


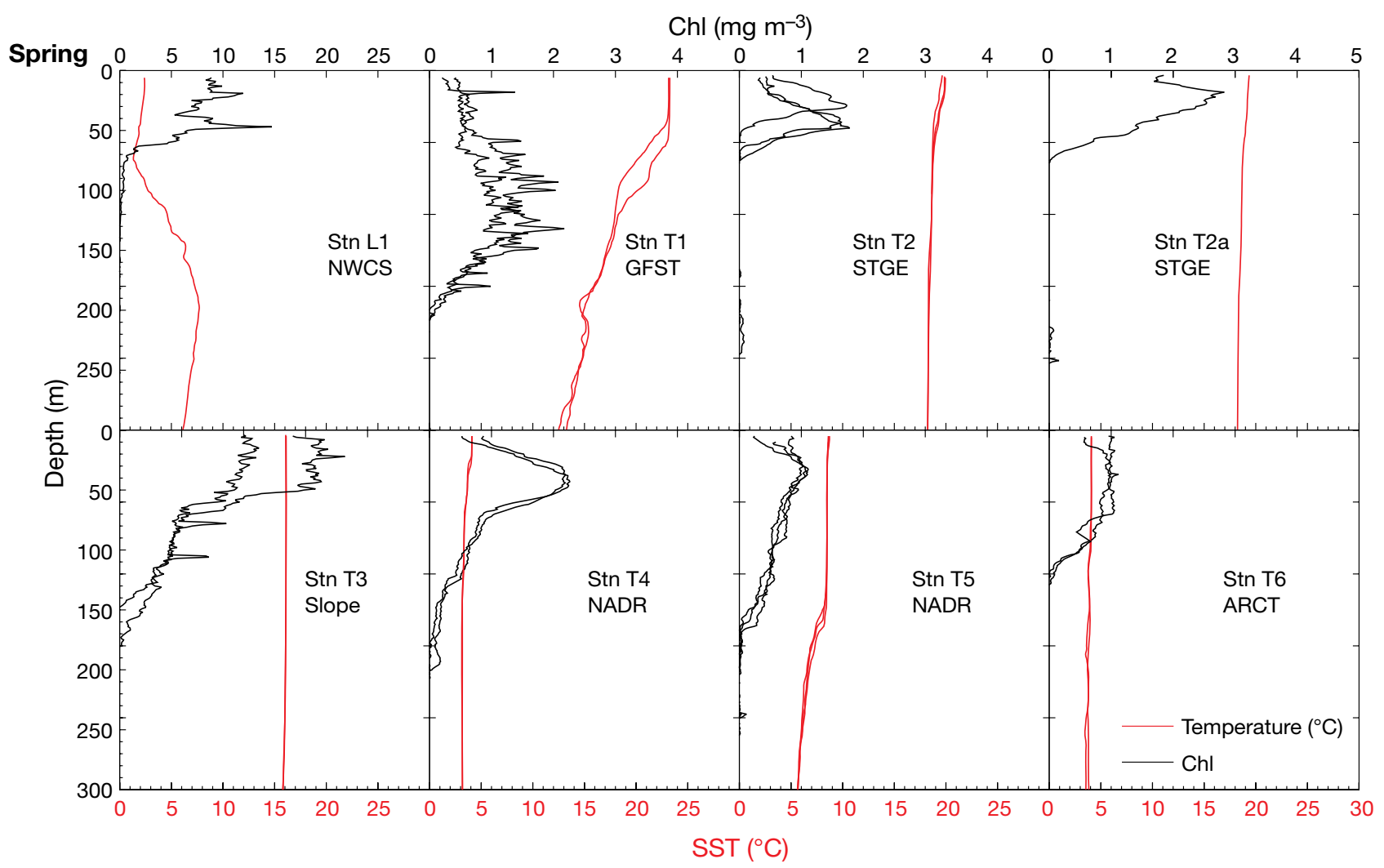

Fig. 7. Temperature and $\mathrm{chl}$ a concentration profiles at fixed stations visited during the C-SOLAS cruises in spring 2003

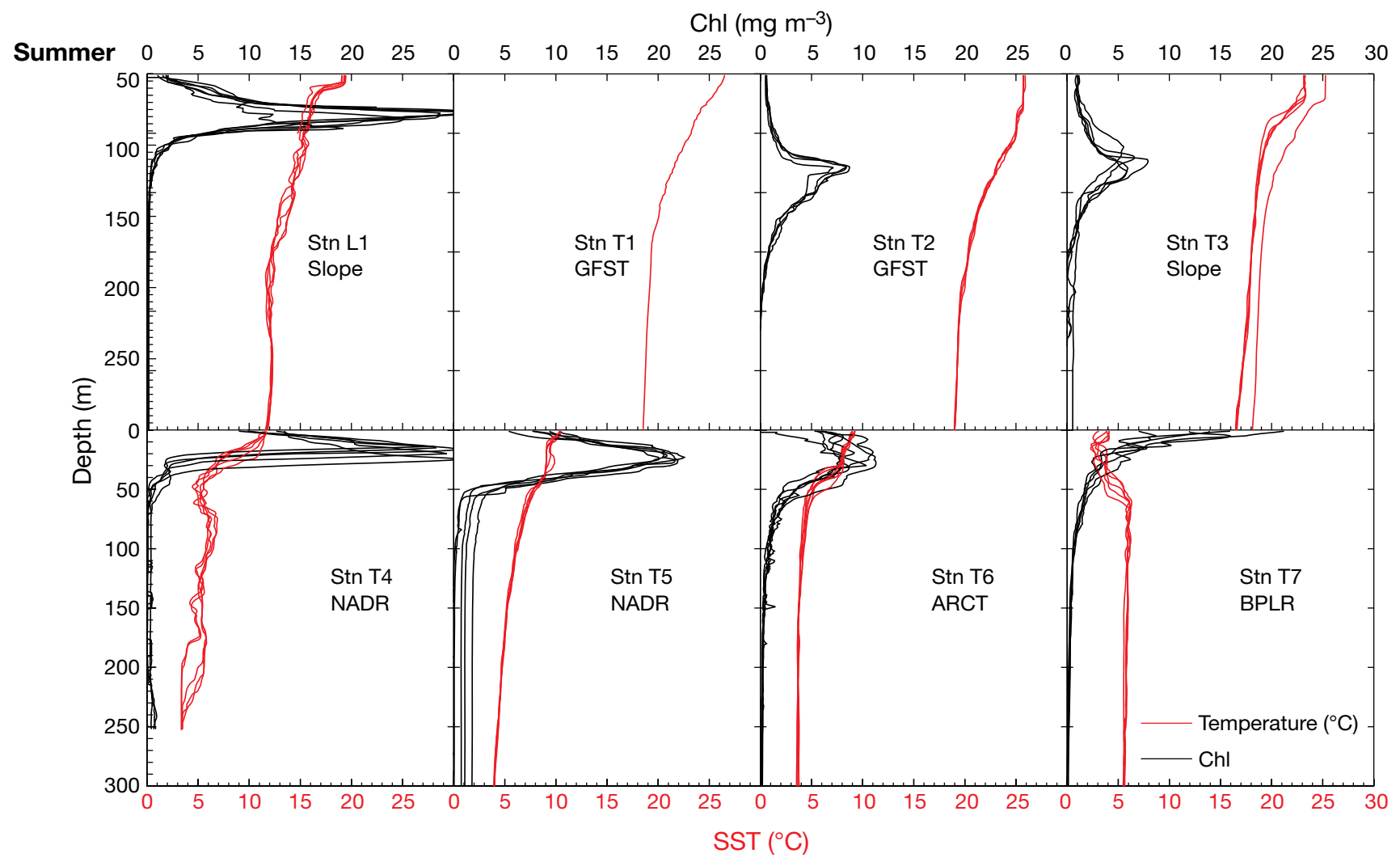

Fig. 8. Temperature and chl a concentration profiles at fixed stations visited during the C-SOLAS cruises in summer 2003 
thermocline was present at a depth of around $50 \mathrm{~m}$, and at Stn L1, located in the NWCS province. At Stn L1, temperature and fluorometry profiles (Fig. 7) indicated low temperatures and high biomass, in agreement with the average values for this province, $4.5^{\circ} \mathrm{C}$ and $3.7 \mathrm{mg} \mathrm{chl} \mathrm{a} \mathrm{m}^{-3}$ (note that the purpose was not to compare a single in situ measurement with an area of a few thousand $\mathrm{km}^{2}$, but rather to gain an indication of the properties of the water masses). At this station, temperatures increased at depths of around $70 \mathrm{~m}$, whereas chl a concentrations decreased. Stns T2 and T2a showed deep chl a maxima at around 40 and $20 \mathrm{~m}$, respectively, typical depths for oligotrophic waters. This was consistent with the STGE province identified using the satellite data, within which these stations were located. Stn T3, located in the Slope province, exhibited a phytoplankton profile similar to that of Stn L1, but with higher values. Stns T4 and T5 were both located in the NADR province, but were separated by more than $10^{\circ}$ of latitude. Both of these stations showed deep chl a maxima at around $40 \mathrm{~m}$ and slow decrease of chl a concentration with depth (up to $150 \mathrm{~m})$, consistent with weak stratification. Stn T6 was located in the ARCT province: no stratification was indicated by the temperature profile and chl a concentrations were homogeneous across the first $75 \mathrm{~m}$ of depth.
In summer, profiles indicated increased stratification (Fig. 8) because of heating of the surface layer and reduced occurrence of storms. Stn L1 was located in the Slope province, where a deep chl a maximum was observed around 30 to $40 \mathrm{~m}$. Statistical analysis classified Stns T1 and T2 as belonging to the GFST province. Fig. 5 shows, on a large scale, that these stations were surrounded by the STGW province. Temperature gradients were smaller in summer than in spring. Our analysis indicated mixing between the subtropical gyre and the Gulf Stream. Temperature profiles for Stns T1 and T2 were very similar; both also had deep chl a maxima (at 60 and $50 \mathrm{~m}$, respectively), consistent with the statistical analysis. Stn T3 was located in the Slope province according to the statistical analysis. The fluorometry profiles were similar to those for Stn T2, but the temperature profiles had a thermocline ( $5 \mathrm{~m}$ ) as did Stn L1, located in the same province. Stns T4 and T5 had similar temperature and fluorometry profiles (smaller amplitude of the fluorometry profile at Stn T5). These profiles were consistent with the satellite-based classification of the provinces, because both stations were located in the NADR province. Stn T6 was located in the ARCT province, and Fig. 8 shows that a thermocline was present around $40 \mathrm{~m}$, deeper than the one observed at Stns T4 and T5 in the NADR province. Profiles recorded at Stn T7 exhibited a very

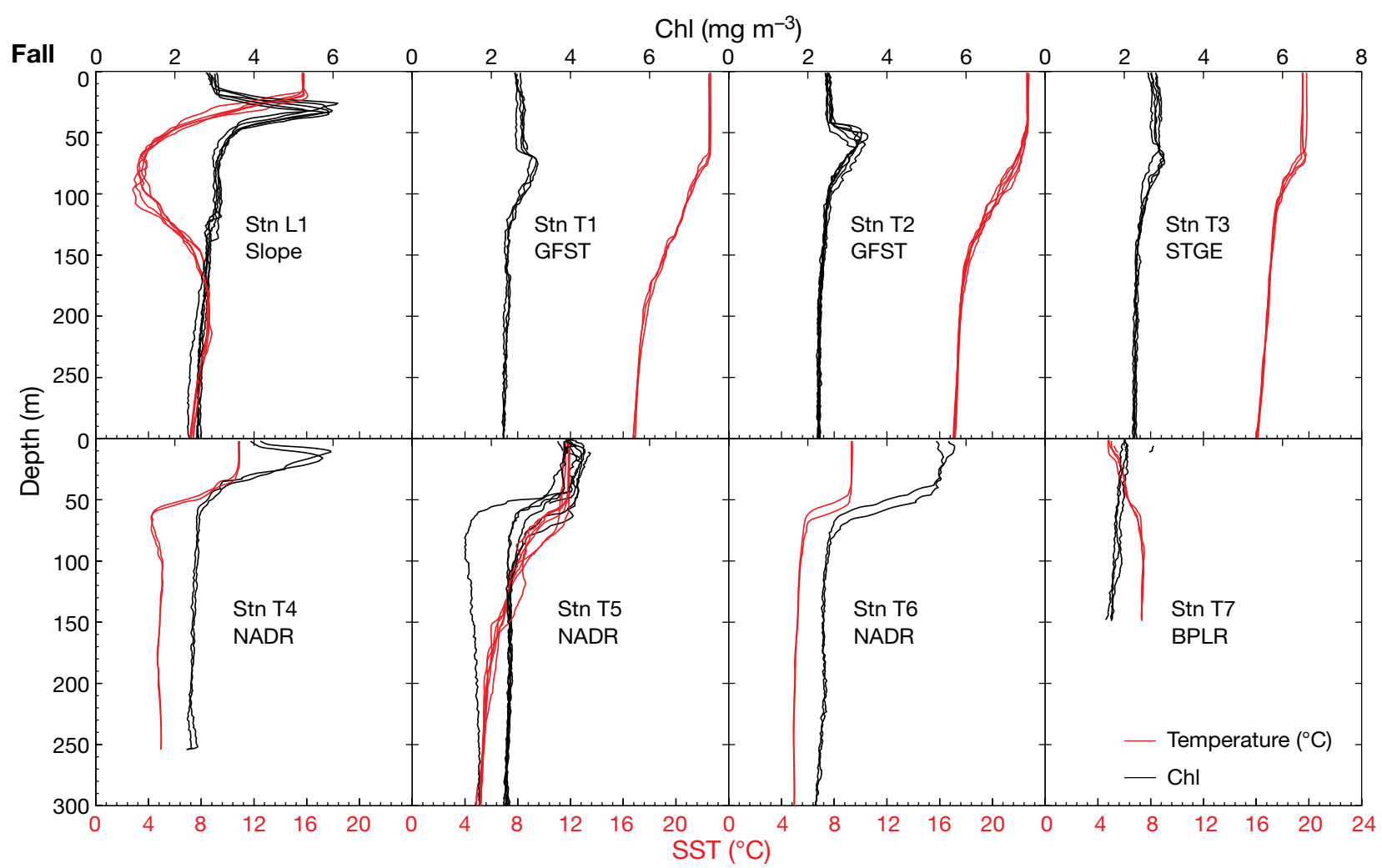

Fig. 9. Temperature and chl a concentration profiles at fixed stations visited during the C-SOLAS cruises in fall 2003 
different pattern from those observed at the other stations, with the chl a maximum occurring close to the surface and temperatures increasing with depth. This was typical for the BPLR province within which the station was located.

CTD profiles recorded at the same stations during the fall illustrated the northward shift of the provinces with the seasons (Fig. 9). Stn L1 remained in the Slope province, where it was during summer. The fluorometry profile exhibited a deep chl a maximum at $40 \mathrm{~m}$ depth. Fluorometry and temperature profiles at Stns $\mathrm{T} 1, \mathrm{~T} 2$ and T3 were characteristic of WOW in agreement with their locations in the GFST (Stns T1 and T2) and STGE provinces. Note that temperature at Stn T3 was lower than at Stns T1 and T2. Stn T4 was located in the NADR province according to the dynamic assignment of provinces. However, temperature and fluorometry profiles showed features similar to those at Stn L1, located in the Slope province. Stns T5 and T6, also located in the NADR province, had similar CTD casts. Stn T7 showed features similar to those during summer, with an increase of temperature with depth and a thermocline located at the same depth as in summer. This station was located in the BPLR province where it was in summer.

\section{Dynamic definition of ecological provinces and primary production}

At the NW Atlantic scale, primary production was of similar magnitude for both definitions of the ecological provinces, with regional values of $141 \times 10^{9}, 175 \times 10^{9}$ and $129 \times 10^{9} \mathrm{gC} \mathrm{d}^{-1}$ for spring, summer and fall, respectively, under the static definition of provinces, and $137 \times 10^{9}, 172 \times 10^{9}$ and $126 \times 10^{9} \mathrm{~g} \mathrm{C} \mathrm{d}^{-1}$ for spring, summer and fall when provinces were dynamically assigned. The agreement between the sets of daily primary production values computed using both definitions of provincial boundaries could be explained by the global assignment of the photosynthetic parameters within domains rather than provinces. This procedure was adopted due to undersampling in some areas (Sathyendranath et al. 1995).

Table 5 shows the contribution of each province (\%) to the total primary production of an area defined by cloud-free provinces in all seasons using the static and dynamic assignments of the provinces for the 3 cruises (spring, summer and fall). The NWCS province was the main contributor to primary production under the static definition, with $>40 \%$ for all seasons. The contribution of the NWCS decreased strongly under the dynamic assignment of the provinces, and the Slope province became the largest contributor to total production during the fall. Contributions to production
Table 5. Contribution of each province (\%) to the total production in the study area for the static and dynamic definition of the ecological provinces for the 3 cruises (spring, summer and fall); -: slope not included in Longhurst et al. (1995)

\begin{tabular}{|llcc|}
\hline & Province & Static & Dynamic \\
\hline Spring & NWCS & 44.7 & 37.7 \\
& GFST & 27.7 & 10.0 \\
& STGE & 2.2 & 14.8 \\
& STGW & 25.4 & 17.2 \\
& Slope & - & 20.3 \\
Summer & NWCS & 41.6 & 33.0 \\
& GFST & 29.2 & 12.8 \\
& STGE & 2.3 & 8.1 \\
& STGW & 26.9 & 19.6 \\
& Slope & - & 26.5 \\
& NWCS & 43.0 & 25.3 \\
& GFST & 28.4 & 16.8 \\
& STGE & 2.2 & 8.5 \\
& STGW & 26.4 & 16.2 \\
& Slope & - & 33.2 \\
\hline
\end{tabular}

decreased generally for all provinces under the dynamic definition, except for the STGE province, the contribution of which increased. The addition of the Slope province explained this general decrease.

\section{DISCUSSION}

The definition of ecological provinces as an aid for understanding biological and physical processes in the ocean ecosystem was assessed on the basis of satellite data. The strength of this method relies on coupling previous knowledge of oceanic provinces to an objective statistical method for accurately defining the boundaries of ecological provinces. Cluster analysis was applied to satellite data (SST and chl a concentration) to sort pixels into ecological provinces in the NW Atlantic. The immediate goal of this approach was to identify the surface water masses within which the fixed stations were located. These stations were visited during 3 research cruises executed by C-SOLAS in 2003. Availability of the dynamic partition (ecological provinces) will improve interpretation of the results (e.g. DMS production, primary production, optical measurements). The accurate definition of province boundaries represents an asset for extrapolating findings at a given station to a larger scale. Although sparse in time and space, temperature and fluorometry profiles at fixed stations showed a good agreement with the definition of the provinces.

Estimation of primary production showed that results from the dynamic assignment of the provinces were consistent with those from the static definition over large scales. The dynamic assignment of the borders of ecological provinces modified the spatial distribution 
of production within the NW Atlantic, and significant differences appeared when comparing the results obtained using the static definition of Longhurst et al. (1995).

The method presented here demonstrates the ability to combine physical and biological data to define ecosystem structure at large scales using a robust statistical method. Including other properties in addition to SST and chl a concentration, such as location and depth, extends the scope of the partition, with the potential to extend the method to the world's oceans.

Acknowledgements. This work was carried out as part of the Canadian SOLAS project. This work was also supported by the Canadian Space Agency (GRIP) and the Department of Fisheries and Oceans, Canada.

\section{LITERATURE CITED}

Bardey P, Garnesson P, Moussu G, Wald L (1999) Joint analysis of temperature and ocean colour satellite images for mesoscale activities in the Gulf of Biscay. Int $\mathrm{J}$ Remote Sensing 20:1329-1341

Cornillon P, Stramma L, Price JF (1987) Satellite measurements of sea surface cooling during Hurricane Gloria. Nature 326:373-375

Dugdale RC, Morel A, Bricaud A, Wilkerson FP (1989) Modeling new production in upwelling centers: a case study of modeling new production from remotely sensed temperature and color. J Geophys Res 94:18119-18132

Dupont F, Hannah CG, Wright DG (2006) Model investigation of the slope water, north of the Gulf Stream. Geophys Res Lett 33:L05604

Fischer G, Ratmeyer V, Wefer G (2000) Organic carbon fluxes in the Atlantic and the Southern Ocean: relationship to primary production compiled from satellite radiometer data. Deep-Sea Res II 47:1961-1997

Gibb SW, Barlow RG, Cummings DG, Rees NW, Trees CC, Holligan P, Suggett D (2000) Surface phytoplankton pigment distributions in the Atlantic Ocean: an assessment of basin scale variability between $50^{\circ} \mathrm{N}$ and $50^{\circ} \mathrm{S}$. Prog Oceanogr 45:339-368

Editorial responsibility: Howard Browman (Associate Editorin-Chief), Storebø, Norway
Gonzalez-Silvera A, del Angel ES, Garcia VMT, Garcia CAE, Nez RMN, Muller-Karger F (2004) Biogeographical regions of the tropical and subtropical Atlantic Ocean off South America: classification based on pigment (CZCS) and chlorophyll-a (SeaWiFS) variability. Cont Shelf Res 24:983-1000

Hartigan JA, Wong MA (1979) A K-means clustering algorithm. Appl Stat 28:100-108

Hoepffner N, Sathyendranath S (1992) Bio-optical characteristics of coastal waters: absorption spectra of phytoplankton and pigment distribution in the western North Atlantic. Limnol Oceanogr 37:1660-1679

Hoepffner N, Sturm B, Finenko Z, Larkin D (1999) Depthintegrated primary production in the eastern tropical and subtropical North Atlantic basin from ocean colour imagery. Int J Remote Sensing 20:1435-1456

Hoge FE, Lyon PE (2005) New tools for the study of oceanic eddies: satellite derived inherent optical properties. Remote Sens Environ 95:444-452

Johannessen OM, Sandven S, Jenkins A, Durand D, Petterson LH, Espedal P, Evensen G, Hamre T (2000) Satellite observation in operational oceanography. Coast Eng 41: 155-176

Longhurst A (2006) The Atlantic Ocean. In: Longhurst A (ed) Ecological geography of the sea, 2nd edn. Elsevier Science Publishers, New York, p 131-268

Longhurst A, Sathyendranath S, Platt T, Caverhill C (1995) An estimate of global primary production in the ocean from satellite radiometer data. J Plankton Res 17: $1245-1271$

Platt T, Sathyendranath S (1993) Estimators of primary production for interpretation of remotely sensed data on ocean colour. J Geophys Res 98:14561-14576

Sathyendranath S, Platt T, Horne EPW, Harrison G, Ulloa O, Outerbridge R, Hoepffner N (1991) Estimation of new production in the ocean by compound remote sensing. Nature 353:129-133

Sathyendranath S, Longhurst A, Caverhill C, Platt T (1995) Regionally and seasonally differentiated primary production in the North Atlantic. Deep-Sea Res 42:1773-1802

Sur H, Oezsoy E, Uenlueat U (1994) Boundary current instabilities, upwelling, shelf mixing and eutrophication processes in the Black Sea. Prog Oceanogr 33:249-302

Watts L, Sathyendranath S, Caverhill C, Maass H, Platt T, Owens T (1999) Modelling new production in the northwest Indian Ocean region. Mar Ecol Prog Ser 183:1-12

Submitted: February 7, 2007; Accepted: June 30, 2007

Proofs received from author(s): August 24, 2007 